\title{
Sphaerospora dicentrarchi and S. testicularis (Myxozoa: Sphaerosporidae) in farmed European seabass (Dicentrarchus labrax) from Italy
}

\author{
Maria Letizia Fioravanti, Monica Caffara, Daniela Florio, Andrea Gustinelli and Federica Marcer \\ Dipartimento di Sanità Pubblica Veterinaria e Patologia Animale, Università di Bologna, Via Tolara di Sopra 50, 40064 Ozzano \\ Emilia, Bologna, Italy
}

Key words: Myxosporea, Sphaerospora dicentrarchi, Sphaerospora testicularis, European seabass, mariculture, epidemiology, Italy

\begin{abstract}
The distribution of Sphaerospora dicentrarchi Sitjà-Bobadilla et Alvarez-Pellitero, 1992 and S. testicularis SitjàBobadilla et Alvarez-Pellitero, 1990, myxozoan parasites of European seabass Dicentrarchus labrax (L.), was investigated in different farming systems in Italy. In total, 1406 fish were examined. High S. dicentrarchi prevalence was observed in all the farming systems involved in this survey (extensive farms: $51.5 \%$; intensive farms: inland $59.6 \%$, inshore floating cages $76.2 \%$, offshore floating cages $41.6 \%$ ) except for submersible cages (7.4\%). S. testicularis was detected only in nine male fish from two intensive farms. The epidemiology and pathological effects of the parasites are discussed.
\end{abstract}

Infections caused by myxozoans have been increasingly considered a health and economic threat for the Mediterranean mariculture over the last decade. Among marine myxosporean parasites, Sphaerospora dicentrarchi Sitjà-Bobadilla et Alvarez-Pellitero, 1992 and S. testicularis Sitjà-Bobadilla et Alvarez-Pellitero, 1990 represent important pathogens of both wild and cultured European seabass Dicentrarchus labrax (L.) in the western Mediterranean basin.

Sphaerospora dicentrarchi, described for the first time in Spain (Sitjà-Bobadilla and Alvarez-Pellitero 1992) is now considered to be one of the most common parasites of European seabass (LeBreton 1999). This histozoic systemic parasite infects the connective tissue of the host, showing particular tropism for the gut, gall bladder and kidney. The pathological effects of $S$. dicentrarchi on cultured seabass are not extensively documented; nevertheless a chronic "cumulative" effect on the host as a consequence of the progressive increase of the infection rate with age was described (SitjàBobadilla and Alvarez-Pellitero 1993a). Furthermore, some authors have suspected its role in immunocompromising the host and favouring the outbreak of opportunistic infections (Rigos et al. 1999, Bruno and Woo 2002).

On the contrary, $S$. testicularis is a coelozoic parasite considered highly pathogenic because of the extensive damage it causes to infected testes (Sitjà-Bobadilla and Alvarez-Pellitero 1993a). The life cycle of both these myxosporeans has not yet been elucidated even if the presence of an alternate host, like in other Sphaerospora species, can be hypothesised (Sitjà-Bobadilla and Alvarez-Pellitero 1993b).
Because of the great commercial importance of the European seabass in Italy, a parasitological survey was carried out in order to better understand the epidemiology of $S$. dicentrarchi and $S$. testicularis in different national farming systems.

\section{MATERIALS AND METHODS}

From January 2000 to June 2003, 1406 European seabass coming from different farming systems were examined to detect the presence of Sphaerospora dicentrarchi and S. testicularis. Seven hundred and eighty-six seabass were sampled from extensive farms and 620 from different intensive farming systems, namely inland farms (124), inshore floating cages (299), offshore floating cages (36) and submersible cages (161). Twenty-one farms were examined, the distribution of which is shown in Fig. 1.

The fish were weighed, measured, necropsied and subjected to a complete parasitological examination. Fresh mounts from the gut, gall bladder, kidney, liver, spleen and gonads (when possible) were microscopically examined for spores of Sphaerospora spp. May-Grünwald-Giemsa-stained smears were also prepared from the gut, gall bladder and kidney. Fresh spores were studied and measured after purification from infected tissues that had been digested according to Muñoz et al. (1998).

The intensity of infection with $S$. dicentrarchi was evaluated by the semi-quantitative method established by SitjàBobadilla and Alvarez-Pellitero (1993b).

Histological sections $(5 \mu \mathrm{m})$ were prepared from infected tissues fixed in $10 \%$ neutral buffered formalin and stained with haematoxylin \& eosin and Giemsa.

This paper was presented at the 6th International Symposium on Fish Parasites in Bloemfontein, South Africa, 22-26 September 2003. 


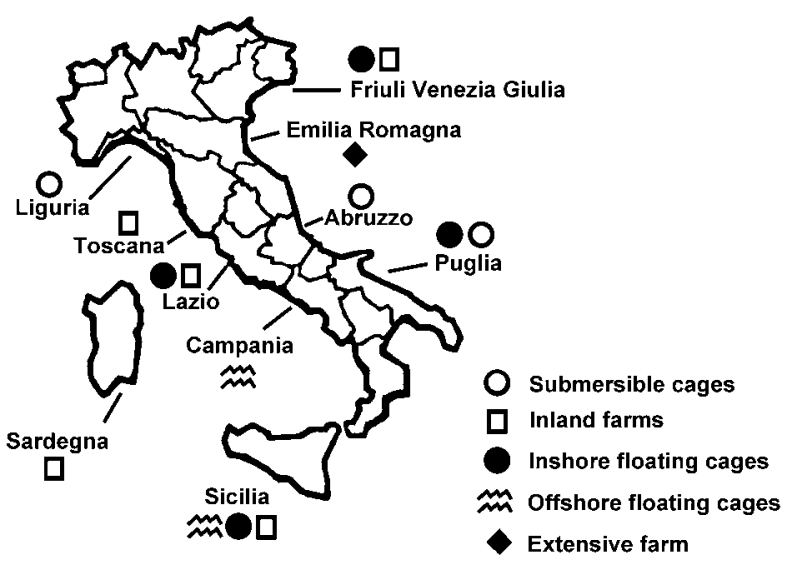

Fig. 1. Distribution of the farming systems investigated along the Italian coast.

A Chi-square test of independence $(\mathrm{p}<0.01)$ was applied in order to analyse the influence of farming system (extensive $v s$ intensive systems, inland farms $v s$ floating cages, inshore $v s$ offshore cages and $v s$ submersible cages) on the prevalence of infection.

\section{RESULTS}

The microscopic examination of fresh and stained smears from several organs, mainly gut, gall bladder and kidney, revealed the presence of bag-like groups of spores in $734(52.2 \%)$ of the seabass examined. The morphological features of the purified spores permitted them to be identified as Sphaerospora dicentrarchi, according to the previous description by Sitjà-Bobadilla and Alvarez-Pellitero (1992).

The following values were found in different farming systems: extensive farms: $51.5 \%$; intensive farms: $53 \%$ (inland: 59.6\%; inshore floating cages: $76.2 \%$; offshore floating cages: $41.6 \%$; submersible cages: $7.4 \%$ ). No statistically significant difference was observed between extensive and intensive farming systems. The statistical analysis of $S$. dicentrarchi prevalence values in the different intensive farming systems has shown a significant difference $(\mathrm{p}<0.01)$, with the exception of inland farms vs offshore floating cages.

Spores were never detected in seabass weighing less than $10 \mathrm{~g}$, and the intensity of infection progressively increased with the size, thus the age, of the host. Although $S$. dicentrarchi was detected throughout the year, infection intensity was always highest in the warm season, with a score $>3+$, evaluated by the method established by Sitjà-Bobadilla and Alvarez-Pellitero (1993b).

The heaviest infection intensity values were always observed in fish from extensive, inland intensive farms and inshore floating cages, with a score ranging from 3 to $5+$.

At the histopathological level, major portions of organs in heavily infected seabass $(>3+)$ exhibited tissue degeneration, especially in the gut, pancreas and kidney. The intestinal submucosa and renal parenchyma revealed haemorrhage and necrosis. In slightly infected seabass $(<3+)$, no significant lesions were observed.

Spores of $S$. testicularis were found only in 9 males weighing over $200 \mathrm{~g}$ from two different intensive farms (inland and inshore floating cages), sampled at the end of the spawning season. The unambiguous identification with $S$. testicularis was based on the original description of this species by Sità-Bobadilla and Alvarez-Pellitero (1990). The infected testes showed macroscopic lesions, such as thickening and darkened coloration with scattered pale nodules. Histopathologically examined seminiferous tubules appeared to be filled with degenerated spores and residual material. A fibrotic reaction was present around the tubules. Cysts and free spores of $S$. dicentrarchi were always detected in the interstitial tissue of the testes infected with $S$. testicularis.

\section{DISCUSSION}

The results of this survey indicate a wide distribution of Sphaerospora dicentrarchi in Italy. Both extensive and intensive systems showed similar values of prevalence, indicating the presence of a common risk factor in these environments. In particular, the higher prevalence observed in extensive farms, intensive inland farms and inshore floating cages seem to indicate the possible involvement of an alternate host, such as benthic annelids, in the life cycle of $S$. dicentrarchi, as already suggested by Sitjà-Bobadilla and Alvarez-Pellitero (1993b). The prevalence values observed in seabass cultured in both offshore floating and submersible cages could be explained by that the fish had previously been for several months in inland farms (pre-fattening stage), where they could have developed the infection.

The increase of the infection intensity during the warm season is in agreement with the observations made by other authors (Sitjà-Bobadilla and AlvarezPellitero 1993b) on $S$. dicentrarchi in Spain. This result could indicate a seasonal colonisation of the environment by an alternate host, as demonstrated for several other myxozoans (Kent et al. 2001).

Sphaerospora dicentrarchi seems to be harmless in light infections, becoming a serious problem at high intensity, mainly under stressful conditions (SitjàBobadilla and Alvarez-Pellitero 1993a, Rigos et al. 1999, Bruno and Woo 2002). We observed severe enteritis in heavily infected seabass especially at the end of summer. The affected subjects were always adults at least two years old, confirming the "cumulative" effect of $S$. dicentrarchi on the host described by SitjàBobadilla and Alvarez-Pellitero (1993a).

A low-grade mortality was sometimes observed in infected subjects weighing over $100 \mathrm{~g}$, often associated with bacterial infections (vibriosis) or bad environmental conditions. It was never possible to attribute 
heavy mortality to $S$. dicentrarchi in fry, as described by Bruno and Woo (2002).

Regarding $S$. testicularis, it has to be stressed that detection of this parasite is possible only in males and mainly during the spawning season (Sitjà-Bobadilla and Alvarez-Pellitero 1993b). Therefore future studies on the distribution of this myxozoan should be carried out on mature males of D. labrax during the spermiation period. Nevertheless, this report indicates the presence of this parasite in Italian farms, confirming its distribution in this Mediterranean area (Rigos et al. 1999). Sporadic infection observed both in Italy and in Greece could be the result of occasional contact between cultured seabass and a natural host, as suggested by SitjàBobadilla and Alvarez-Pellitero (1993b).

A previous observation of a monoxenous life cycle of $S$. testicularis among seabass maintained in experimental tanks (Sitjà-Bobadilla and Alvarez-Pellitero 1993b) could explain why the parasite was only found in intensive farms but not in extensive systems.

It may be concluded that infection with $S$. dicentrar$c h i$ is widely spread in the aquaculture systems in Italy, where it can now be considered one of the most common parasites of cultured seabass. This parasite can cause chronic infections, causing production losses and a higher susceptibility to stresses or opportunistic pathogens.

Sphaerospora testicularis exhibited a more restricted distribution in Italian aquaculture, confirming the necessity to clarify its epidemiology and the possible existence of a natural host. Even if our survey permitted the first record of this important pathogen in Italy, further investigations must be carried out to define its actual distribution in order to evaluate the infection risk for European seabass breeding stock.

The lack of adequate therapy for myxosporean parasites makes urgent the improvement of knowledge of the life cycle of $S$. dicentrarchi and $S$. testicularis to define prophylactic measures in aquaculture.

Acknowledgements. This research was supported by MIPAF (Ministry of Agriculture of Italy). The authors thank all the marine farmers who co-operated during this survey and Dr. Trina Kudlacek for reviewing the English language.

\section{REFERENCES}

BRUNO D.W., WOO P.T.K. 2002: Sporadic, emerging diseases and disorders. In: P.T.K. Woo, D.W. Bruno and L.H.S. Lim (Eds.), Diseases and Disorders of Finfish in Cage Culture. CABI Publishing, Wallingford, UK, pp. 305-343.

KENT M.L., ANDREE K.B., BARTHOLOMEW J.L., ElMATBOULI M., DESSER S.S., DEVLIN R.H., FEIST S.W., HEDRICK R.O., HOFFMAN R.W., KHATTRA J., HALLETT S.L., LESTER R.J.G., LONGSHAW M., PALENZUELA O., SIDDALL M.E., XIAO C. 2001: Recent advances in our knowledge of the Myxozoa. J. Eukaryot. Microbiol. 48: 395-413.

LeBRETON A. 1999: Mediterranean finfish pathologies: present status and new developments in prophylactic methods. Bull. Eur. Assoc. Fish Pathol. 19: 250-253.

MUÑOZ P., SITJÀ-BOBADILLA A., ALVAREZ-PELLITERO P. 1998: Immunohistochemical characterization of a polyclonal antibody against Sphaerospora dicentrarchi (Myxosporea: Bivalvulida), a parasite from sea bass ( $\mathrm{Di}$ centrarchus labrax L.) (Teleostei: Serranidae). Parasitol. Res. 84: 733-740.

RIGOS G., CHRISTOPHILOGIANNIS P., YIAGNISI M., ANDRIOPOULOU A., KOUTSODIMOU M., NENGAS I., ALEXIS M. 1999: Myxosporean infections in Greek mariculture. Aquaculture Int. 7: 361-364.
SITJÀ-BOBADILLA A., ALVAREZ-PELLITERO P. 1990: Sphaerospora testicularis sp. nov. (Myxosporea: Sphaerosporidae) in wild and cultured sea bass, Dicentrarchus labrax (L.), from the Spanish Mediterranean area. J. Fish Dis. 13: 193-203.

SITJÀ-BOBADILLA A., ALVAREZ-PELLITERO P. 1992: Light and electron microscopic description of Sphaerospora dicentrarchi $\mathrm{n}$. sp. (Myxosporea: Sphaerosporidae) from wild and cultured sea bass, Dicentrarchus labrax L. J. Protozool. 39: 273-281.

SITJÀ-BOBADILLA A., ALVAREZ-PELLITERO P. 1993a: Pathologic effects of Sphaerospora dicentrarchi SitjàBobadilla and Alvarez-Pellitero, 1992 and S. testicularis Sitjà-Bobadilla and Alvarez-Pellitero, 1990 (Myxosporea: Bivalvulida) parasitic in the Mediterranean sea bass Dicentrarchus labrax L. (Teleostei: Serranidae) and the cell-mediated immune reaction: a light and electron microscopy study. Parasitol. Res. 79: 119-129.

SITJÀ-BOBADILLA A., ALVAREZ-PELLITERO P. 1993b: Population dynamics of Sphaerospora dicentrarchi Sitjà Bobadilla and Alvarez-Pellitero, 1992 and S. testicularis Sitjà-Bobadilla and Alvarez-Pellitero, 1990 (Myxosporea: Bivalvulida) infections in wild and cultured Mediterranean sea bass (Dicentrarchus labrax L.). Parasitology 106: 3945 .

Accepted 3 May 2004 